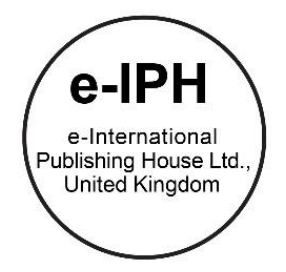

\title{
Assessing the Quality of Overall Planning for Public Preschools at Klang Valley in Malaysia
}

\author{
Mariam Felani Shaari ${ }^{1}$, Sabarinah Sheikh Ahmad ${ }^{1}$, Izaham Shah Ismail ${ }^{2}$ \\ 1 Faculty of Architecture, Planning and Surveying, Universiti Teknologi MARA, 40450 Shah Alam, Selangor, Malaysia \\ 2 Faculty of Education, Universiti Teknologi MARA, 42300 Bandar Puncak Alam, Selangor, Malaysia \\ mariamfelani87@gmail.com sabar643@uitm.edu.my izaha740@uitm.edu.my \\ Tel: +60125060875
}

\begin{abstract}
Poor overall planning leads to overcrowding in preschools. Ample space and a low teacher-child ratio in activity spaces are crucial. This paper investigates and proposes improvements to the overall planning quality of 26 Malaysian public preschools in Klang Valley. Four planning aspects were assessed (building size, size of indoor activity spaces, enrolment and quality of modules) using the Children's Physical Environment Rating Scale. Most preschools were too small and the average planning quality of the studied preschools was only rated Fair. Design recommendations discussed in this paper will help designers devise better planning for Malaysian preschools in the future.
\end{abstract}

Keywords: building size; children's activity spaces; preschool design; learning environment

eISSN: 2398-4287 @ 2020. The Authors. Published for AMER ABRA cE-Bs by e-International Publishing House, Ltd., UK. This is an open access article under the CC BYNC-ND license (http://creativecommons.org/licenses/by-nc-nd/4.0). Peer-review under responsibility of AMER (Association of Malaysian Environment-Behaviour Researchers), ABRA (Association of Behavioural Researchers on Asians) and cE-Bs (Centre for Environment-Behaviour Studies), Faculty of Architecture, Planning \& Surveying, Universiti Teknologi MARA, Malaysia.

DOI: https://doi.org/10.21834/ebpj.v5iSI1.2289

\subsection{Introduction}

Children are the future leaders of the world. Due to the vital role they play, their potential to develop and flourish to be great leaders should be maximized. Thus, the importance of providing young children with excellent quality early childhood education has been advocated globally. The preschool period is considered crucial in developing physical, intellectual, social, and emotional competence (Christensen et al., 2014; David \& Weinstein, 2013), thus, ensuring individual success (Raja Harun et al., 2005). However, for preschools to fully maximize the children's development, preschool lessons must be conducted not only using high-quality curriculum and pedagogy but also in high-quality physical settings (Loebach, 2005). The crucial need for high-quality schooling experience at the preschool level is due to young children's susceptibility to the surrounding environment as compared to adults. Young children are found to be more sensitive towards their environment; thus, the experiences they encounter during childhood will significantly affect the way they conduct themselves later in life (Ozcan, 2006).

In Malaysia, good well-known pedagogies such as Montessori have long been adopted in preschools. Unfortunately, it is a norm that these pedagogies are being conducted in poor quality preschool settings (Mohidin et al., 2015). Issues of poor preschool building design were often reported in local literature (Abbas et al., 2016; Ahmad et al., 2015; Azhari et al., 2015). This may be due to the lack of awareness and understanding of what constitutes a good quality preschool setting among stakeholders.

Many design factors determine preschool building quality, and one of them is overall planning (building capacity). Poor overall planning of preschools is commonly associated with overcrowding issues. Preschools that are too dense with a high teacher-child ratio pose many negative impacts on children's behavior, attention, development, and academic achievement. Therefore, prompt actions to improve preschool building quality are required to ensure our future leaders get the best start in life. Failure to do so will jeopardize their potential to be fully developed and prosperous. In response, this paper aims to investigate and propose an improvement to the overall planning quality (focusing on overcrowding issues) of public preschool buildings governed by the Ministry of Education (MOE) Malaysia.

eISSN: 2398-4287 @ 2019. The Authors. Published for AMER ABRA cE-Bs by e-International Publishing House, Ltd., UK. This is an open access article under the CC BYNC-ND license (http://creativecommons.org/licenses/by-nc-nd/4.0). Peer-review under responsibility of AMER (Association of Malaysian Environment-Behaviour Researchers), ABRA (Association of Behavioural Researchers on Asians) and cE-Bs (Centre for Environment-Behaviour Studies), Faculty of Architecture, Planning \& Surveying, Universiti Teknologi MARA, Malaysia.

DOI: https://doi.org/10.21834/ebpj.v5iSl1.2289 
It also discusses design recommendations to improve preschool capacity through building sizes, activity spaces sizes as well as modules.

\subsection{Literature Review}

Many physical elements can influence children learning and development including aspects of the built preschool environment that affect the child's behavior and developmental trajectory (Acar, 2014). Scholars such as Berris \& Miller (2011) believe that for preschools to maximize children's development, learning programs must be supported by a properly designed physical learning environment. Ample space for learning activities goes a long way to ensure that academic teaching and its impact on children is maximized.

The preschool period is crucial for the development of a child's personality as well as their physical, emotional, social and cognitive abilities. As Shute \& Slee (2015) argue, within this short time, children learn and develop exponentially. Therefore, supporting their developmental processes at the preschool stage must go hand-in-hand with their age.

Overall building size and size of activity spaces matter in preschool building design. In large childcare centers, children aged two (2) to four (4) years old are often overwhelmed by the number of staff and the overall building size (Berris \& Miller, 2011). While parents often assume that bigger is better, children may not share the same perspective. Educators too have described how the overall center size can be both encouraging and intimidating to children. Further, educators often note that big centers gave children room to work, helps dilute noise and made visual supervision easier but often overwhelm them and lead to confusion and anxiety (Rentzou, 2014).

Conversely, when accounting for the benefits of smaller classroom sizes and overall costs involved for such a setting, centers of 60 to 75 children are best, both for the child and the staff (Moore, 2012). Ideally, Overall building size for the preschool should be at least $11 \mathrm{~m}^{2} /$ child, and another 9 to $10 \mathrm{~m}^{2} /$ child for outdoor play yards, driveways, drop-offs, and set-backs to allow ample space for all activity areas (David \& Weistein, 2013; Moore, 2012). These dimensions, therefore, must be taken into consideration in overall size allocation for preschools.

In preschool design terminology, a "module" is defined as a set of physically and functionally separated spaces for a group of children. It pertains to the part of the preschool building where children spend most of their time, where most of their functional needs and primary child-focused teaching-learning activities occur. Moore (2012) states that smaller centers may have just one or two "modules" while others may and should have a larger number of "modules" to keep group sizes to a minimum. Modules can be interconnected, semi-detached, or entirely freestanding parts of the preschool building. Nevertheless, the purpose of modules is to make sure that children's group sizes are minimized to promote better learning experiences in preschools.

These aspects of space and building size have long been enforced in preschools of developed countries but have often been found to be overlooked among Malaysian preschools (Abbas \& Othman, 2012); more emphasis is needed to improve overall planning and quality of design among preschools in Malaysia. Hence, it is unsurprising the cognitive level and academic achievements of most Malaysian pre-schoolers in public preschools were only found to be average when compared to national and international standards (Majzub \& Rashid, 2012).

Finally, to evaluate these crucial aspects, the Children's Physical Environment Rating Scale (CPERS) offers an ideal tool. Unlike other assessment tools, CPERS allows for the assessment of preschool physical aspects concerning their capability to promote cognitive development among children. This is most appropriate for the study because the Ministry of Education (MOE) envisions preschools to maximize cognitive development among preschool children (MOE, 2016).

\subsection{Method}

\subsection{Research Design}

The methodology of this study was emulated from previous related studies (Abbas et al., 2016; Azhari et al., 2015) on the assessment of preschool physical environments. The fieldwork was conducted in the natural setting of preschools, using the Children's Physical Environment Rating Scale (CPERS) that uses the 5-point rating scale. The independent variables are the selected preschools. Because this study is a subset of the overall preschool physical environments study, the dependent variables of this study are confined to the CPERS (Part A: Planning - Subscale 1) scores.

\subsection{Location}

As opposed to previous studies, which are all conducted in Selangor, this research is distinctive as it focuses on a larger region in Malaysia - Klang Valley. Klang Valley consists of the federal territory of Kuala Lumpur and four areas of Selangor - Petaling, Klang, Hulu Langat, and Gombak. Both urban and non-urban areas of Klang Valley are covered for comparative purposes.

\subsection{Sample}

This study is conducted in Malaysia's Ministry of Education (MOE) public preschools. The MOE public preschools are preschools located within the vicinity of MOE public primary schools. They serve children aged five to six years old. However, due to time and cost constraints, the sample was scoped down only to preschools that serve six-year-old children and built from 2002 to 2016 . For this research, 26 out of 30 preschools are assessed upon approval. 


\subsection{Limitation}

This study is confined to preschools with the above criteria (the type of preschool, location, built year, and age of children served); thus, other unrelated preschools are excluded. Therefore, any findings obtained from this study could not be generalized to other populations. However, similar studies about different sets of criteria could be done in future research. Additionally, only one evaluator was employed in this study to evaluate all participating preschools. Although best efforts have been made to maintain consistency of assessment, biasness may be present in the evaluation process. Moreover, this study is only interested in overall planning quality, thus, only (Part A: Planning) of CPERS is used. Other parts (Part B, Part C, and Part D) of CPERS are examined in the next phase of the study.

\subsection{Procedure 1: Consenting}

Five stages of the consenting process are accomplished before the start of the field study as illustrated in Figure 1.

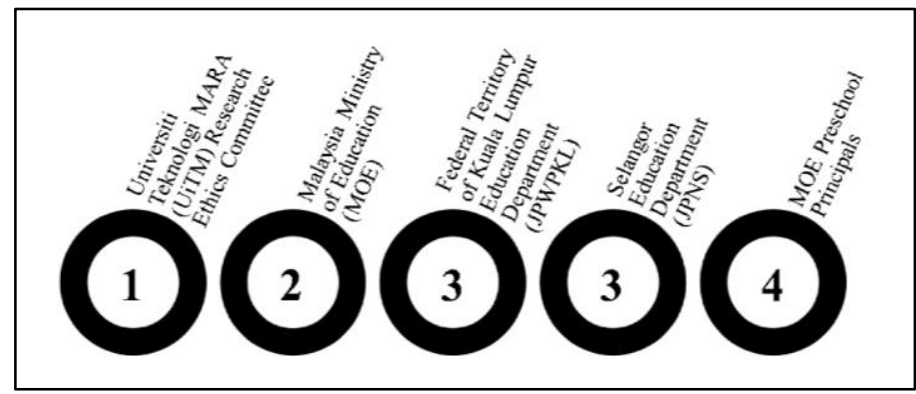

Fig. 1: Research Consenting Stages

(Source: Author)

Upon approval, preschool building floor plans are made available by the principals of participating preschools. However, the researchers prepared the measured drawings of preschools without floor plan drawings before the assessments. Moreover, preschool background information forms are distributed to preschool teachers. Teachers are expected to fill in the form with details such as the preschool's name, address, name of the principal, contact details (phone, fax, e-mail), current enrolment, built year, and built purpose. The forms are returned by hand at the end of the assessment.

\subsection{Procedure 2: Pilot Study}

The researchers conducted a pilot assessment prior to actual evaluation for self-acquaintance of the proposed instrument - CPERS, and assessment procedure. It is also done to foresee and address any potential issues related to the proposed tool and method before commencing the actual assessment.

\subsection{Procedure 3: Data Collection (Actual Assessment)}

The 26 selected preschool buildings are individually observed and assessed using the CPERS (Part A: Planning). The preschools are scored based on the existence of particular items in Part A of CPERS, and how well the quality of the individual elements are. The assessment duration for each preschool varied between 1 and 2 hours depending on the availability of floor plans prior to the field study, size, and complexity of the preschool buildings.

\subsection{Procedure 4: Data Analysis}

Every item and overall raw scores of CPERS (Part A: Planning) of all studied preschools are gathered, calculated, finalized and coded in the Statistical Package for the Social Sciences (SPSS). The scores are then statistically analyzed to gauge the individual as well as the average quality of overall planning of the 26 studied preschool buildings. The individual and average quality of each item in the CPERS (Part A: Planning) of the 26 studied preschool buildings are also analyzed for design improvement recommendation purposes.

\subsection{Findings}

The overall planning quality of the preschools is assessed in the first part (Part A) of CPERS. The four aspects of planning, namely the Building Size, Useable Indoor Activity Space Size, Enrolment, and Modules, are evaluated in each preschool to gauge the quality. Different scores indicate different quality levels as follows:

$$
\begin{aligned}
\text { i. } & 3.01-4.00=\text { Excellent } \\
\text { ii. } & 2.01-3.00=\text { Good } \\
\text { iii. } & 1.01-2.00=\text { Fair } \\
\text { iv. } & 0.00-1.00=\text { Poor }
\end{aligned}
$$

\subsection{CPERS Part A: Planning}

Table 1 shows the Mean score of CPERS (Part A) for all the observed preschools $(N=26)$ is 1.52 . This indicates that the average quality of overall planning of the preschools falls under the Fair category. The minimum and maximum scores reveal that some of the preschools receive scores as low as 0.00 and as high as 2.67 , respectively. 
Table 1: Average CPERS (Part A: Planning) Score

\begin{tabular}{lllllll} 
PART A: PLANNING & $\mathrm{N}$ & Range & Min. & Max. & Mean & Quality \\
\cline { 2 - 7 } Subscale 1: Center Size \& Modules & 26 & 2.67 & 0.00 & 2.67 & 1.52 & Fair \\
\hline
\end{tabular}

Table 2 distributes the CPERS (Part A) scores for all the studied preschools ( $N=26)$ according to their quality levels. It is revealed that none of the preschools scored Excellent for planning quality. Table 2 shows $26.9 \%(N=7)$ of them have Good quality, half $-50 \%$ $(N=13)$ of them have Fair condition, while the remaining $23.1 \%(N=6)$ have Poor quality.

Table 2: Distribution of CPERS (Part A: Planning) by Quality

PART A: PLANNING

Subscale 1: Center Size \& Modules

\begin{tabular}{llllll} 
& \multicolumn{5}{l}{ Distribution of Scores by Quality } \\
\cline { 2 - 5 } Overall & Excellent & Good & Fair & Poor \\
& $3.01-4.00$ & $2.01-3.00$ & $1.01-2.00$ & $0.00-1.00$ \\
\hline$\%$ & 100 & 0 & 26.9 & 50 & 23.1 \\
$\mathrm{~N}$ & 26 & 0 & 7 & 13 & 6 \\
\hline \multicolumn{5}{c}{ (Source: Author) }
\end{tabular}

\subsection{Planning Aspects: Building Size, Useable Indoor Activity Space Size, Number of Enrolment, and Number of Modules}

Table 3 below lists the building sizes (total gross areas), useable indoor activity space sizes, number of enrolment (maximum number of children served at one time) as well as the number of modules for each assessed preschools. Overall, the preschools' building sizes range between $95.04 \mathrm{~m}^{2}$ and $652.88 \mathrm{~m}^{2}$, while their useable indoor activity areas range between $60.00 \mathrm{~m}^{2}$ and $226.80 \mathrm{~m}^{2}$. Meanwhile, the maximum number of enrolment range is between 25 and 75 children. Moreover, only six preschools are designed to have two modules, while most of the preschools are built with a single module.

Table 3: Building Size, Useable Activity Area, Number of Enrolment, and Module of the Studied Preschools

\begin{tabular}{lllll}
\hline Preschool $(\mathrm{N}=26)$ & Building Size $\left(\mathrm{m}^{2}\right)$ & Useable Indoor Activity Space Size $\left(\mathrm{m}^{2}\right)$ & Number of Enrolment & Number of Module \\
\hline 1 & 652.88 & 139.40 & 50 & 1 \\
2 & 315.54 & 60.00 & 25 & 1 \\
3 & 305.51 & 160.00 & 50 & 1 \\
4 & 174.75 & 63.98 & 25 & 2 \\
5 & 236.35 & 157.00 & 25 & 1 \\
6 & 216.53 & 119.70 & 25 & 1 \\
7 & 220.90 & 142.68 & 25 & 1 \\
8 & 481.18 & 226.80 & 75 & 1 \\
9 & 562.27 & 212.34 & 75 & 1 \\
10 & 184.60 & 130.29 & 25 & 1 \\
11 & 153.10 & 73.79 & 50 & 2 \\
12 & 230.28 & 163.52 & 25 & 1 \\
13 & 390.22 & 182.40 & 75 & 1 \\
14 & 254.82 & 179.08 & 50 & 1 \\
15 & 130.00 & 82.94 & 25 & 2 \\
16 & 123.12 & 65.13 & 25 & 1 \\
17 & 235.60 & 162.75 & 25 & 1 \\
18 & 732.20 & 159.60 & 50 & 1 \\
19 & 149.10 & 61.97 & 50 & 2 \\
20 & 112.47 & 72.80 & 25 & 1 \\
21 & 286.45 & 133.70 & 50 & 1 \\
22 & 249.50 & 120.90 & 50 & 2 \\
23 & 95.04 & 63.83 & 25 & 2 \\
24 & 131.40 & 63.00 & 25 & 25 \\
25 & 256.85 & 165.86 & 25 & 2 \\
26 & 263.53 & 160.00 & & \\
\hline
\end{tabular}

Table 4 lists the Mean scores of each CPERS (Part A) Items - Items 1.1- 1.6 of the studied preschools. The Mean scores for Items 1.1-1.3 are derived from all $(\mathrm{N}=26)$ the studied preschools. However, the Mean scores for Items 1.4-1.6 are only calculated from 6 preschools, as the items are only applicable to preschools that have more than 1 module.

The Mean scores shown in Table 4 reveal that the average quality of building size and the useable indoor space size of the studied preschools is Poor. However, the average quality of their Enrolment is Excellent. For preschools that have more than 1 module, the average quality ratings of having their Entrances and Play Yards for each module are Excellent and Good respectively. However, the average quality rating of having a clear Separation between modules is only Fair.

Table 4: Average CPERS (Part A: Planning) Items Score

\begin{tabular}{lllllll}
\hline PART A: PLANNING & N & Range & Min & Max & Mean & Quality \\
Subscale 1: Center Size \& Modules & 26 & 4 & 0 & 4 & 0.46 & Poor \\
\hline Item 1.1 Building Size & 26 & 4 & 0 & 4 & 0.54 & Poor \\
Item 1.2 Useable Indoor Activity Space Size & 26 & 4 & 0 & 4 & 3.15 & Excellent \\
Item 1.3 Enrolment & & & & & &
\end{tabular}




\begin{tabular}{llllllll} 
Item 1.4 Modules - Own Entrances & 6 & 2 & 2 & 4 & 3.33 & Excellent \\
Item 1.5 Modules - Own Play Yards & 6 & 4 & 0 & 4 & 2.33 & Good \\
Item 1.6 Modules - Separation & 6 & 4 & 0 & 4 & 1.83 & Fair \\
\hline
\end{tabular}

Table 5 shows that it is ideal to have a preschool building size greater than $11 \mathrm{~m}^{2}$ per child. However, only $11.54 \%(\mathrm{~N}=3)$ of preschools have this. The rest of the preschools have a building size of less than $9 \mathrm{~m}^{2}$ per child.

For useable indoor activity space, it is ideal for a preschool to provide the area with a size of greater than $4 \mathrm{~m}^{2}$ per child. However, only $11.54 \%(\mathrm{~N}=3)$ of the studied preschools have them. Most of the preschools or $84.61 \%(\mathrm{~N}=22)$ of them have space sized less than $3 \mathrm{~m}^{2}$ per child. Only one preschool $(3.85 \%)$ has an area sized between $3.5 \mathrm{~m}^{2}$ and $4.0 \mathrm{~m}^{2}$ per child. Most of the studied preschools or $69.23 \%(\mathrm{~N}=18)$ served less than 40 children per module at one time. Only five preschools $(19.23 \%)$ served between 40 to 50 children, and the remaining three preschools $(11.54 \%)$ served more than 50 children at one time.

For preschools that have more than one module, it is critical to ensure that all of the modules have their entry and play yard, and can easily be identified as separate sections of the preschool building. As previously explained, only 6 out of 26 studied preschools have more than a single module, meaning 20 preschools are run on two modules. Table 5 shows that 4 out of 6 preschools have an independent entry for each module. Three out of 6 preschools have separate play yard that is directly accessible from the interior of each module. However, only one preschool has a clear separation between modules and can easily be identified as separate sections of the building.

Table 5: Detail of CPERS (Part A: Planning) Items Scores

\begin{tabular}{|c|c|c|c|c|c|}
\hline \multicolumn{3}{|c|}{$\begin{array}{l}\text { PART A: PLANNING } \\
\text { Subscale 1: Center Size \& Modules }\end{array}$} & Score & $\begin{array}{l}\% \\
100\end{array}$ & $\begin{array}{l}\mathrm{N} \\
26\end{array}$ \\
\hline \multirow{3}{*}{ Item 1.1} & \multirow{3}{*}{ Building Size per Child (m²/child) } & Less than $9 \mathrm{~m}^{2}$ & 0 & 88.46 & 23 \\
\hline & & Between $9 \mathrm{~m}$ and $11 \mathrm{~m}^{2}$ & 2 & 0 & 0 \\
\hline & & Greater than $11 \mathrm{~m}^{2}$ & 4 & 11.54 & 3 \\
\hline \multirow{3}{*}{ Item 1.2} & \multirow{3}{*}{ Useable Indoor Activity Space Size per Child ( $\left.\mathrm{m}^{2} / \mathrm{child}\right)$} & Less than $3.5 \mathrm{~m}^{2}$ & 0 & 84.61 & 22 \\
\hline & & Between $3.5 \mathrm{~m}^{2}$ and $4.0 \mathrm{~m}^{2}$ & 2 & 3.85 & 1 \\
\hline & & Greater than $4.0 \mathrm{~m}^{2}$ & 4 & 11.54 & 3 \\
\hline \multirow{3}{*}{ Item 1.3} & \multirow{3}{*}{ Enrolment per Module (children/module) } & Greater than 50 & 0 & 11.54 & 3 \\
\hline & & Between 40 and 50 & 2 & 19.23 & 5 \\
\hline & & Less than 40 & 4 & 69.23 & 18 \\
\hline \multirow{2}{*}{\multicolumn{3}{|c|}{$\begin{array}{l}\text { PART A: PLANNING } \\
\text { Subscale 1: Center Size \& Modules }\end{array}$}} & \multirow{2}{*}{ Score } & $\%$ & $\mathrm{~N}$ \\
\hline & & & & 100 & 26 \\
\hline \multirow{5}{*}{ Item 1.4} & \multirow{5}{*}{ Modules - Own Entrances } & Not Met & 0 & 0 & 0 \\
\hline & & & 1 & 0 & 0 \\
\hline & & & 2 & 33.33 & 2 \\
\hline & & & 3 & 0 & 0 \\
\hline & & Fully Met & 4 & 66.67 & 4 \\
\hline \multirow{5}{*}{ Item 1.5} & \multirow{5}{*}{ Modules - Own Play Yards } & Not Met & 0 & 33.33 & 2 \\
\hline & & & 1 & 0 & 0 \\
\hline & & & 2 & 16.67 & 1 \\
\hline & & & 3 & 0 & 0 \\
\hline & & Fully Met & 4 & 50 & 3 \\
\hline \multirow{5}{*}{ Item 1.6} & \multirow{5}{*}{ Modules - Separation } & Not Met & 0 & 33.33 & 2 \\
\hline & & & 1 & 16.67 & 1 \\
\hline & & & 2 & 0 & 0 \\
\hline & & & 3 & 33.33 & 2 \\
\hline & & Fully Met & 4 & 16.67 & 1 \\
\hline
\end{tabular}

(Source: Author)

\subsection{Discussion and Recommendations}

In summary, due to Fair average quality, it is strongly suggested that the overall planning of the studied preschools need immediate improvement. Figure 2 illustrates the improvement rating of the four aspects (Building Size, Useable Indoor Activity Space Size, Enrolment, and Modules) of the overall planning. The evaluation is made based on the CPERS (Part A) Subscale Items (Items 1.1-1.6) Mean scores. An item with the lowest Mean score is placed first in the improvement rank and vice versa.

As illustrated, the aspect of Building Size has the lowest Mean score; thus, it ranked first and needs immediate improvement. Such improvement could then be conducted on the element of Useable Indoor Activity Space and Enrolment. Additionally, further improvements are required for preschools with more than one module. The element of Separation between Modules has the lowest Mean score, thus, ranked as the first aspect that needs improvement. Improvements in Play Yards and Entrances should also be conducted.

All preschools should have the right capacity to accommodate their children and activities. Preschools with a higher number of enrolment should be larger in size and vice versa. To determine the ideal preschool building size, size of greater than $11 \mathrm{~m}^{2}$ per child is the most recommended. Building size of less than $9 \mathrm{~m}^{2}$ per child is too small and inadequate to cater to the overall function of preschools. 


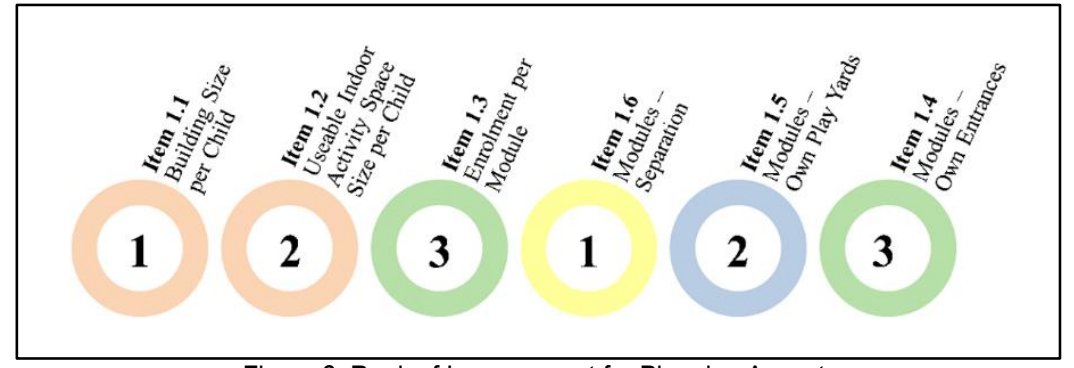

Figure 2: Rank of Improvement for Planning Aspects

(Source: Author)

Some children's activities may require larger spaces than another. However, Shonkof \& Phillips (2001), NICHD (1999) and Ruopp et al. (1979) reported the importance of activity spaces being kept to a low teacher-child ratio due to its many advantages on children. Teachers could make more stimulating, supportive, responsive and warmer interactions with pupils when they have a small teacherchild proportion (Vandell \& Wolfe, 2000). Spaces higher than $4 \mathrm{~m}^{2}$ per child are strongly recommended. Areas lower than $3.5 \mathrm{~m}$ per child should be avoided as it is considered too small and inconvenient.

Modules function as separate building units serving most of the children's functional (eating, sleeping, toilet) and developmental (play activities) needs as demonstrated in Figure 3 below. It helps to keep the teacher-child ratio to a minimum as ideally, the smaller the building size and the fewer children being served at one time, the better. More modules are needed in high-density preschools. Instead of catering children in one large building, it is better for the building be physically compartmented into smaller units (modules) so that the children can enjoy the same benefits of learning in a smaller and lower density preschool. However, each module should be of high quality, generally characterized by having an entry (so that the children, staff, and parents can directly access their modules without having to walk through the rest of the preschool), own play yards (easily accessible from inside), and separated with different architectural elements (spatial arrangement, rooflines, porches, or other easily identifiable parts of buildings).

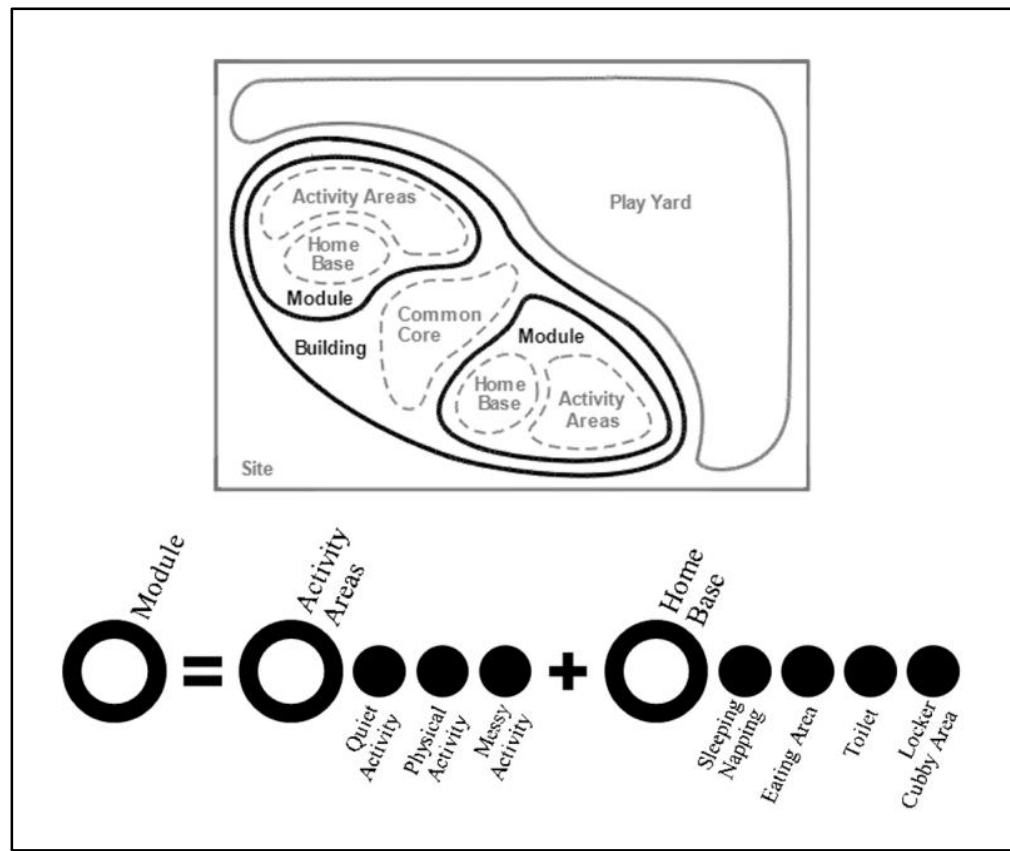

Figure 3: Preschool Module (Source: Moore, 2012)

\subsection{Conclusion}

In conclusion, the overall planning of preschool buildings needs careful consideration and thought. It is crucial to ensure that preschool buildings have enough capacity to serve the children and to run the preschool programs effectively. Therefore, decisions on building sizes, activity spaces sizes, as well as the number of modules provided in each preschool, should be made simultaneously with their number of enrolment. The Fair Mean score of CPERS (Part A) in this study indicates that the overall planning of the studied preschools needs urgent improvement. Planning aspects with lower quality, namely Building Size, Useable Indoor Space Sizes as well as Modules Separation need to be improved urgently. It is hoped that the preschool building planning guidelines discussed in this study will help stakeholders improve existing preschools as well as produce more high-quality preschools soon. 


\section{Acknowledgments}

The authors would like to express their gratitude to the Ministry of Higher Education of Malaysia for providing the Fundamental Research Grant Scheme (FRGS), reference: 600-RMI/FRGS 5/3 (113/2015). Special appreciation is also conveyed to Professor Gary T Moore for the complimentary use of the Children's Physical Environments Rating Scale (CPERS5) in this research.

\section{References}

Abbas, M. Y., Othman, M., \& Rahman, P. Z. M. A. (2016). Pre-School Children's Play Behaviour Influenced by Classroom's Spatial Definitions? Asian Journal of Environment-Behaviour Studies, 1(1), 49-65.

Acar, H. (2014). Learning environments for children in outdoor spaces. Procedia - Social and Behavioral Sciences, 141, 846-853.

Ahmad, S. S., Shaari, M. F., Hashim, R., \& Kariminia, S. (2015). Conducive attributes of physical learning environment at preschool level for slow learners. ProcediaSocial and Behavioral Sciences, 201, 110-120.

Anonymous (2016). Physical Learning Environment: Impact on Children School Readiness in Malaysian Preschools. Procedia-Social and Behavioral Sciences, 222, 918

Azhari, N. F. N., Qamaruzaman, N., Bajunid, A. F. I., \& Hassan, A. (2015). The quality of physical environment in workplace childcare centers. Procedia-Social and Behavioral Sciences, 202, 15-23.

Berris, R., \& Miller, E. (2011). How design of the physical environment impacts on early learning: Educators' and parents' perspectives. Australasian Journal of Early Childhood, 36(4), 102-110.

Christensen, D. L., Schieve, L. A., Devine, O., \& Drews-Botsch, C. (2014). Socioeconomic status, child enrichment factors, and cognitive performance among preschoolage children: results from the Follow-Up of Growth and Development Experiences study. Research in developmental disabilities, 35(7), $1789-1801$.

David, T. G., \& Weinstein, C. S. (Eds.). (2013). Spaces for children: The built environment and child development. Springer Science \& Business Media.

Loebach, J. (2005). Designing learning environments for children: An affordance-based approach to providing developmentally appropriate settings. (Master dissertation, Master of Environmental Design Studies, Dalhousie University, Halifax, Nova Scotia, Canada).

Majzub, R. M., \& Rashid, A. A. (2012). School readiness among preschool children. Procedia - Social and Behavioural Sciences, 46, 3524-3529.

Ministry of Education (MOE) (2016). Kurikulum Standard Prasekolah Kebangsaan. Pendidikan Prasekolah - Dokumen Standard Kurikulum dan Pentaksiran.

Mohidin, H. H. B., Ismail, A. S., \& Ramli, H. B. (2015). Effectiveness of Kindergarten Design in Malaysia. Procedia-Social and Behavioral Sciences, $202,47-57$.

Moore, G. T. (2012). Update on The Children's Physical Environments Rating Scale (CPERS5). Children Youth and Environments, 22(2), 311-312.

NICHD Early Child Care Research Network. (1999). Child outcomes when child care center classes meet recommended standards for quality. American Journal of Public Health, 89(7), 1072-1077.

Ozcan, H. (2006). Healing design: A holistic approach to social interaction in pediatric intensive care units in the United States and Turkey (Doctoral dissertation, Texas A \& M University, USA).

Raja Harun, R.H., Kamri, B., \& Megat Abdul Rahman, P.Z. (2005). Tadika Berkualiti. Batu Caves, Selangor: PTS Profesional Publishing Sdn. Bhd.

Ruopp, R., Travers, J., Glantz, F., \& Coelen, C. (1979). Final report of the National Day Care Study: Children at the center. Volume I: Summary findings and their implications. Cambridge, MA: Abt Associates.

Shute, R. H., \& Slee, P. T. (2015). Child development: Theories and critical perspectives. Routledge.

Shonkoff, J. P., \& Phillips, D. A. (2001). From neurons to neighborhoods: The science of early childhood development. Zero to three, National Academies Press, 21(5) 4-7.

Vandell, D., \& Wolfe, B. (2000). Child care quality: Does it matter and does it need to be improved? (Vol. 78). University of Wisconsin, Madison, Institute for Research on Poverty. 